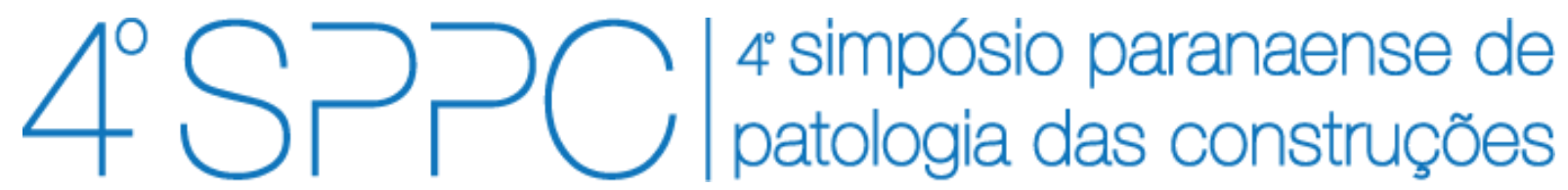

ISSN 2526-7248 artigo n. 4SPPC115, pp. 124-135, 2019

\title{
Análise das manifestações patológicas de um edifício que sofreu recalque diferencial
}

Bortoli, Matheus Fajardo'; Hirano, Eduardo Lovera²; Bressiani, Lucia ${ }^{3}$; Savaris, Gustavo ${ }^{4}$; Balestra, Carlos Eduardo Tina ${ }^{5}$

${ }^{1}$ Engenheiro Civil, Universidade Tecnológica Federal do Paraná, matheusfbortoli@hotmail.com

${ }^{2}$ Acadêmico do Curso de Engenharia Civil, Universidade Tecnológica Federal do Paraná, eduardoloverahirano@gmail.com

${ }^{3}$ Doutora em Engenharia Civil, Universidade Tecnológica Federal do Paraná, bressiani@utfpr.edu.br

${ }^{4}$ Doutor em Engenharia Civil, Universidade Tecnológica Federal do Paraná, gsavaris@utfpr.edu.br

${ }^{5}$ Doutor em Engenharia Civil, Universidade Tecnológica Federal do Paraná, carlosbalestra@utfpr.edu.br email

Resumo: Este trabalho apresenta um estudo de caso de uma perícia realizada em um edifico que sofreu recalque diferencial. Para isso, foram analisadas as consequências provocadas na edificação em função do recalque sofrido. Os procedimentos metodológicos contemplaram a identificação das manifestações patológicas e análise das possíveis causas de acordo com a literatura e análise do laudo pericial. Da mesma forma, foi verificado o tipo de reforço de fundação utilizado comparando com outros métodos apresentados na literatura. Como resultados temse que as fissuras encontradas em $45^{\circ}$ localizadas, assim como as anomalias na base dos pilares, a rachadura vertical em um dos pilares e a rachadura no muro de divisa foram causados pelo movimento negativo do solo, ou seja, pelo recalque diferencial.

Palavras-chave: Recalque diferencial, fissuras, mapeamento, reforço de fundação.

Abstract: This paper shows a case study of a skill case made on a building that underwent differential settlement. In this sense, analysis of the consequences on the building in response of the settlement were made. The methodological procedures contemplated the identification of the pathological manifestations and analysis of the possible causes according to literature and analysis of the expert report. Similarly, it was verified the foundation reinforcement type utilized comparing with others methods presented in literature. Results have shown that the located $45^{\circ}$ degrees cracks, as the anomalies at the base of the pillars, the vertical crack at one of the pillars and the crack on the boundary wall were caused by the negative soil movement originated by the differential settlement.

Keywords: Differential repression, fissures, mapping, foundation reinforcement. 
BORTOLI, M.F.; HIRANO, E.L.; BRESSIANI, L.; SAVARIS, G.; BALESTRA, C. E. T. ANÁLISE DAS MANIFESTAÇÕES PATOLÓGICAS DE UM EDIFÍCIO QUE SOFREU RECALQUE DIFERENCIAL. $4^{\circ}$ Simpósio Paranaense de Patologia das Construções (40 SPPC), artigo 4SPPC115, pp. 124 - 135, 2019. DOI: 10.4322/2526-7248.035

\section{Introdução}

A estrutura é o componente principal de uma edificação. Ela é responsável por garantir a estabilidade da construção, a qual é submetida a diversos tipos de esforços e carregamentos, todos transferidos para a fundação, que quando corretamente dimensionada garante a funcionalidade da estrutura.

E assim como na medicina, a engenharia também realiza estudo das doenças, ciência essa denominada de "Patologia". Na engenharia, chamada de "Patologia das Construções", tem como objetivo o estudo das origens, causas, mecanismos de ocorrência, manifestação e consequências dos problemas que podem vir a interferir na vida útil e finalidade de uma edificação.

Valente, Silva e Calixto [1] citam que a realidade da construção civil no Brasil apresenta um grande número de edificações com manifestações patológicas, que podem ter suas origens nas etapas de planejamento, projeto, execução, uso ou manutenção dos edifícios.

O surgimento de problemas patológicos em uma estrutura, por sua vez, está relacionado a diversos fatores, sendo muitas vezes decorrência de um conjunto destes, que acabam por desencadear em anomalias na edificação (TUTIKIAN; PACHECO [2]).

Uma das causas das manifestações patológicas com maior significância é o recalque diferencial. O recalque ou assentamento é o termo designado na engenharia civil para caracterizar o fenômeno que ocorre quando uma edificação sofre um rebaixamento devido ao adensamento do solo sob sua fundação (MILITITSKY; CONSOLI; SCHNAID [3]).

Nesse sentido, o estudo em questão apresenta a análise de um caso de um edifício que sofreu recalque diferencial, buscando identificar as consequências geradas. Da mesma forma, buscou analisar a solução aplicada para o reforço da fundação, comparando com outras possíveis soluções pertinentes ao caso.

\section{Manifestações patológicas devido a fundação}

As fundações são causas muito frequentes de rachaduras e outras lesões em prédios. Por isso também é frequente atribuir-se às fundações defeitos que não são causadas por elas (VERÇOZA [4]).

As manifestações em fundações, assim como na edificação de um modo geral, podem ocorrer em qualquer fase da obra. As manifestações patológicas em fundações são as deformações ocasionadas devido ao movimento da estrutura do solo. As quais, por sua vez, podem ser ocasionadas nas fases de investigação do subsolo, análise e projeto das fundações, execução das fundações, eventos pósconclusão das fundações, degradação dos materiais constituintes das fundações (MILITITSKY; CONSOLI; SCHNAID [3]). 
BORTOLI, M.F.; HIRANO, E.L.; BRESSIANI, L.; SAVARIS, G.; BALESTRA, C. E. T. ANÁLISE DAS MANIFESTAÇÕES PATOLÓGICAS DE UM EDIFÍCIO QUE SOFREU RECALQUE DIFERENCIAL. $4^{\circ}$ Simpósio Paranaense de Patologia das Construções (40 SPPC), artigo 4SPPC115, pp. 124 - 135, 2019. DOI: 10.4322/2526-7248.035

O problema mais comum é o chamado recalque diferencial. De acordo com Verçoza [4], o fato é que na prática o terreno muitas vezes não possui uma homogeneidade, de modo que algumas estacas possam estar em um ponto do terreno onde a resistência do solo é maior ou menor do que a resistência encontrada na estaca vizinha. Esse fato, faz com que haja, por mais que mínimos, recalques em diferentes alturas. E, com isso, a viga que une essas estacas, quando esse fenômeno ocorre, sofre um abaulamento.

O abaulamento, por sua vez, ainda segundo o mesmo autor, vem a causar uma abertura em ângulo na parede sobreposta a essa viga. Ou seja, a fissura terá uma abertura tanto maior, quanto mais alto o nível da parede. E, além disso, é possível que a viga de fundação não mostre a lesão a olho nu, e que esta apareça somente na alvenaria.

Os danos causados pelas manifestações patológicas das fundações são divididos, por Milititski, Consoli e Schnaid [3], em três grupos. Os danos arquitetônicos ou estéticos são aqueles que comprometem a estética, mas não a estrutura do edifício, como por exemplo, trincas em paredes e desaprumos. Os danos funcionais são os que de algum modo atrapalham na funcionalidade do prédio, causando o mau funcionamento das instalações prediais, como o rompimento de instalações hidráulicas e sanitárias, por exemplo. Há também os danos estruturais, os quais comprometem a estabilidade da estrutura, de modo que se necessite de reforços para que a mesma não venha ao colapso.

\section{Materiais e métodos}

O edifício selecionado para realização do estudo de caso sofreu um recalque diferencial em decorrência de fortes chuvas. Com isso, foi isolado e interditado pela Coordenadoria Regional de Defesa e Proteção Civil. O edifício possui quatro pavimentos, sendo o pavimento térreo composto pela garagem e os outros três pavimentos superiores com seis apartamentos em cada um.

As etapas da pesquisa contemplaram:

a) Análise do laudo pericial: com o incidente do edifício, fez-se necessário a avaliação estrutural da edificação, o monitoramento dos deslocamentos estruturais, como também a determinação das prováveis causas da ocorrência das anomalias e manifestações patológicas. Desta forma, foi analisado o laudo pericial para verificar todos os problemas levantados, bem como possíveis causas. Da mesma forma, o objetivo foi verificar o tipo de reforço de fundação utilizado.

b) Levantamento das anomalias e identificação das possíveis causas: de modo a se analisar e classificar a fundo as manifestações patológicas do edifício em estudo, foi feito o levantamento de todas as fissuras encontradas na edificação, de modo a classificá-las e distingui-las de acordo com a literatura estudada. Esse levantamento foi realizado com a medição da abertura de fissuras, como também foi realizado o registro fotográfico para a realização de outros procedimentos da pesquisa. Além disso, foi identificado o local de cada uma das fissuras, para que pudessem ser analisadas posteriormente como um conjunto. Com esse levantamento de fissuras foi 
BORTOLI, M.F.; HIRANO, E.L.; BRESSIANI, L.; SAVARIS, G.; BALESTRA, C. E. T. ANÁLISE DAS MANIFESTAÇÕES PATOLÓGICAS DE UM EDIFÍCIO QUE SOFREU RECALQUE DIFERENCIAL. $4^{\circ}$ Simpósio Paranaense de Patologia das Construções (40 SPPC), artigo 4SPPC115, pp. 124 - 135, 2019. DOI: 10.4322/2526-7248.035

realizada a metodologia do mapa de danos, para melhor visualização de todas as fissuras existentes. De acordo com Tinoco [5], o Mapa de Danos é um documento do tipo gráfico-fotográfico, que tem como objetivo sintetizar o resultado das investigações sobre as alterações estruturais e funcionais nos materiais, nas técnicas, nos sistemas e componentes construtivos. No caso do estudo, o Mapa de Danos foi utilizado para demarcar as fissuras encontradas nas fachadas externas e mapear as áreas de maior incidência em paredes onde houve recorrência da manifestação patológica tratada na pesquisa. Além da identificação das fissuras, foi identificado no local outras anomalias que poderiam ser decorrentes do recalque diferencial. Para identificar as causas das anomalias foi utilizada a literatura sobre o assunto, bem como o laudo pericial.

c) Análise da solução para o reforço da fundação: a última etapa da pesquisa consistiu na análise da solução utilizada para recuperação da estrutura, comparando com as soluções apresentadas na literatura.

\section{Resultados e discussões}

\subsection{Análise das manifestações patológicas}

A maioria das fissuras internas encontradas foram as horizontais, nas portas de entrada dos apartamentos, enquanto as inclinadas nos cantos das janelas como indicado na Figura 1.
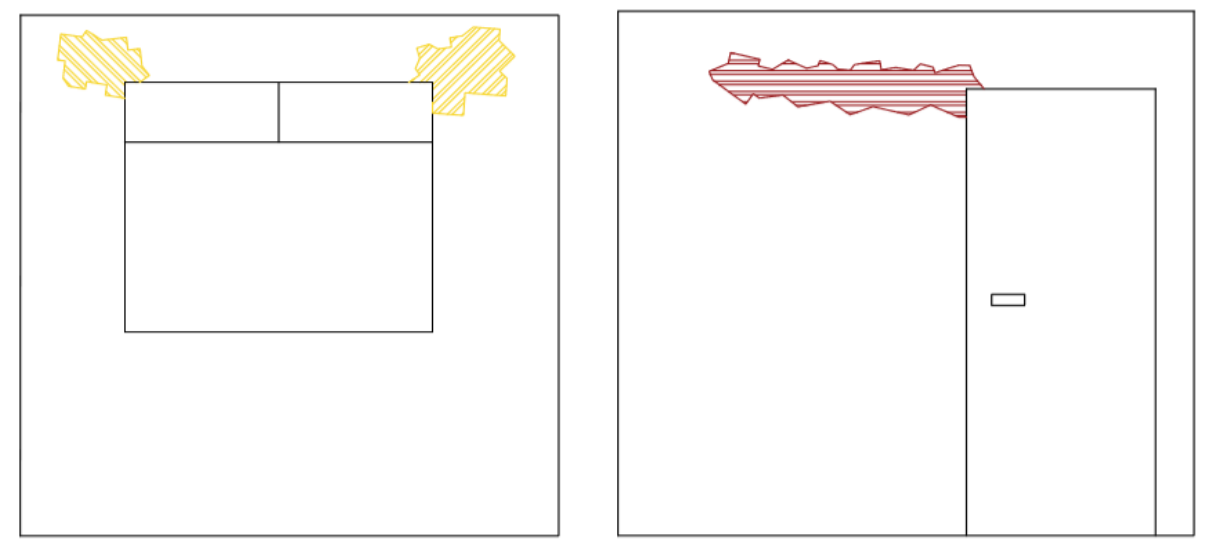

Figura 1: Fissuras internas

Ao realizar o levantamento das fissuras encontradas no local de estudo, analisou-se também, além da orientação de sua incidência, a sua extensão. Essa análise foi realizada de modo a identificar tendências ou sequências das fissuras com as intensidades geradas pelo recalque diferencial.

Percebeu-se que, visualmente, as fissuras tinham dimensões e espessuras menores, quanto mais longe estavam do ponto crítico do recalque diferencial, que ocorreu na fachada leste do edifício. Ou seja, quanto mais alto o cômodo se encontra, e mais longe da extremidade leste do terreno, menores foram as fissuras encontradas. 
BORTOLI, M.F.; HIRANO, E.L.; BRESSIANI, L.; SAVARIS, G.; BALESTRA, C. E. T. ANÁLISE DAS MANIFESTAÇÕES PATOLÓGICAS DE UM EDIFÍCIO QUE SOFREU RECALQUE DIFERENCIAL. $4^{\circ}$ Simpósio Paranaense de Patologia das Construções (40 SPPC), artigo 4SPPC115, pp. 124 - 135, 2019. DOI: 10.4322/2526-7248.035

A Figura 2 apresenta casos de fissuras encontradas no interior de um dos apartamentos do edifício, ou seja, uma fissura a $45^{\circ}$ e uma fissura horizontal.

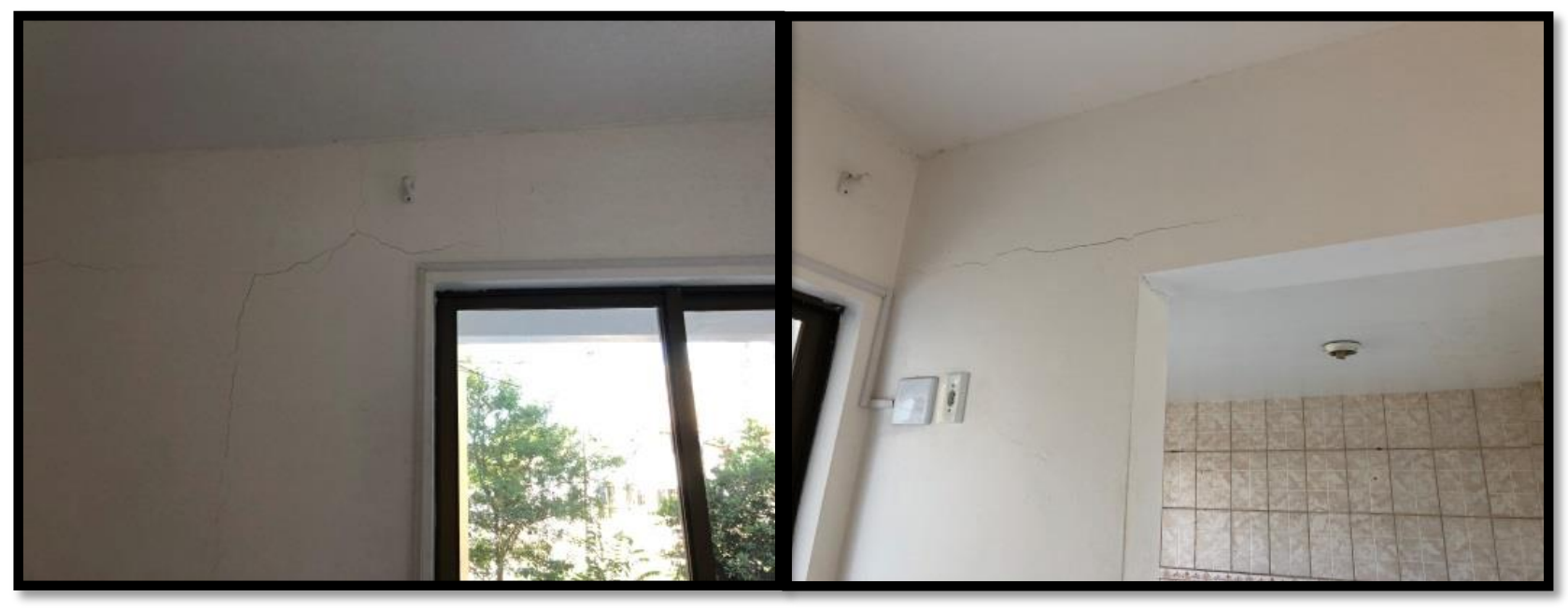

Figura 2: Exemplo de fissuras

A Figura 3 esquematiza a incidência das fissuras causadas pelo recalque diferencial, onde a área em vermelho apresenta os locais de incidências com danos de maior proporção, ao passo que os pontos em verde apresentam os locais de incidências com danos de menor proporção.

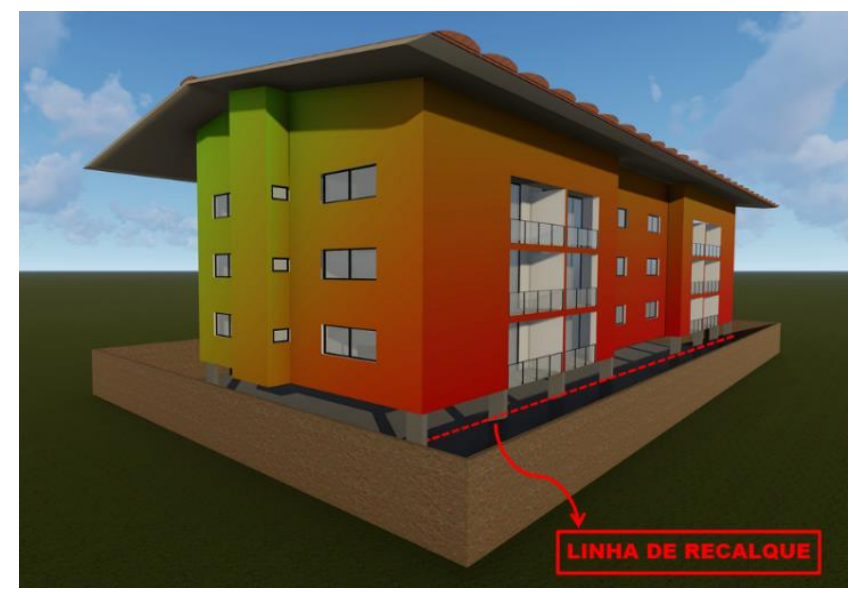

Figura 3: Incidência de fissuras conforme a distância da extremidade do recalque

De acordo com BRE [6] recalque do solo devido à retirada de água por vegetação próxima e expansão por saturação do solo, geram fissuras no lado da edificação próximo à vegetação e geralmente inclinadas.

De acordo com Colares [7] é difícil prever as fissuras em função do recalque da fundação em função da heterogeneidade do solo. Junior [8] ressalta que geralmente essas fissuras se desenvolvem em direção vertical ou diagonal, apresentando variação da abertura ao longo do comprimento. 
BORTOLI, M.F.; HIRANO, E.L.; BRESSIANI, L.; SAVARIS, G.; BALESTRA, C. E. T. ANÁLISE DAS MANIFESTAÇÕES PATOLÓGICAS DE UM EDIFÍCIO QUE SOFREU RECALQUE DIFERENCIAL. $4^{\circ}$ Simpósio Paranaense de Patologia das Construções (40 SPPC), artigo 4SPPC115, pp. 124 - 135, 2019. DOI: 10.4322/2526-7248.035

Com relação à origem das fissuras encontradas nos ambientes internos das edificações, podem ser destacas as seguintes considerações.

De acordo com Thomaz [9], as fissuras em $45^{\circ}$ na alvenaria podem ser originadas a partir de recalques diferenciais, e geralmente inclinam-se em direção ao ponto de maior recalque. Tal situação foi analisada próximo às esquadrias de janelas e portas, onde as fissuras possuíam uma regularidade como explicitada pela literatura. Para (Thomaz [10]), as alterações diagonais são provenientes do rompimento por tração do material

Já as fissuras horizontais, para Thomaz [9], caracterizam situações de tração e compressão do concreto e também destacas no laudo da perícia realizado. Para Sampaio [11] também podem ser provenientes de cargas uniformemente distribuídas.

Alexandre [12] cita que fissuras horizontais também podem ocorrer devido ao esmagamento da argamassa das juntas de assentamento, ou devido a solicitações de flexo-compressão, provenientes da deformação da laje, ou devido a carregamento excêntricos

Durante a coleta de dados realizou-se também o levantamento das fissuras nas fachadas. Deste modo, buscou-se representar graficamente duas fachadas da edificação a fim de mapear as fissuras encontradas, de modo a representar todas elas e analisá-las posteriormente (Figura 4). Para isso, utilizou-se as fachadas sul e leste do edifício residencial. As demais fachadas apresentaram o mesmo comportamento.
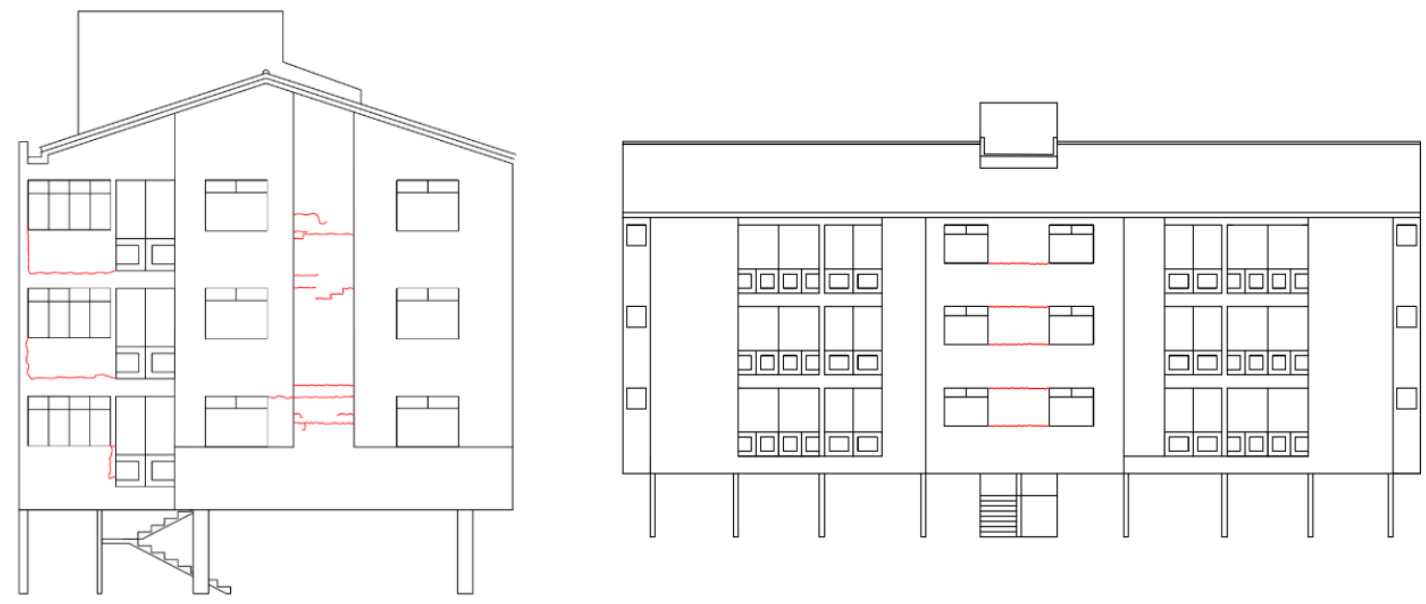

Figura 4: Mapeamento de fissuras das fachadas do edifício

É notória a uniformidade da manifestação patológica encontrada nas fachadas, uma vez que as fissuras horizontais tendem a acompanhar as extremidades superiores e inferiores das vigas estruturais do edifício. De modo que, quase na sua totalidade isso se deve pela junção do concreto (viga estrutural) para com a alvenaria. Isso pode ocorrer, de acordo com Thomaz [9], pelo fato das movimentações térmicas desses materiais se darem de formas diferentes. 
Quanto às fissuras verticais encontradas na fachada, essas podem terem sido causadas também pela junção de elementos como o concreto para com a alvenaria. De modo que surgissem os mesmos danos citados acima.

Foi constatado também que a fachada apresenta alguns aspectos de umidade e infiltração, demonstrando que as mesmas já se encontravam na fachada antes da ocorrência do recalque. Ao redor da abertura, percebeu-se aspectos mais escuros de infiltração e bolor da alvenaria e do revestimento em argamassa (Figura 5).

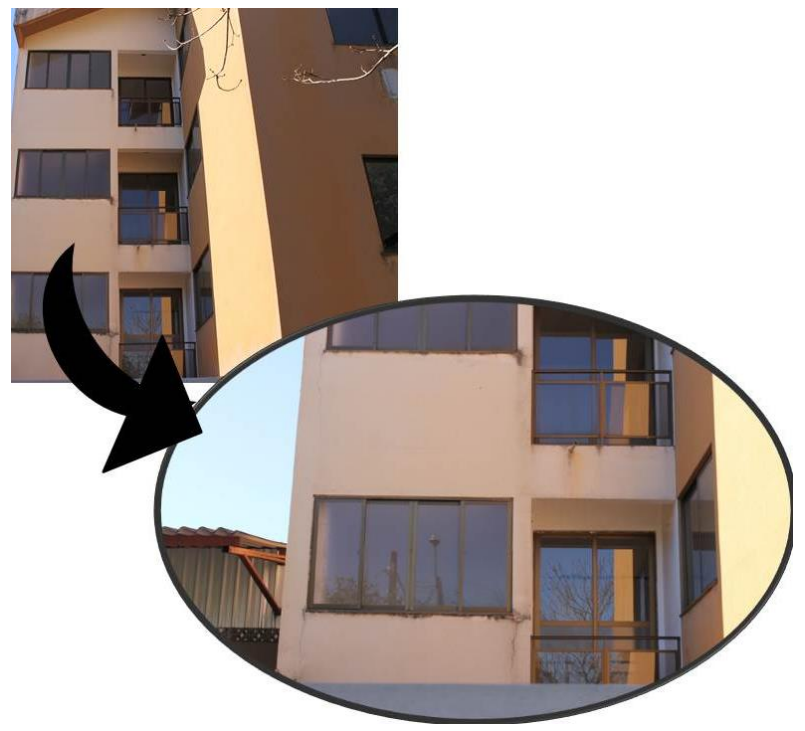

Figura 5: Fissuras com bolor

Com essas análises, confirmadas também pelo laudo técnico realizado após o ocorrido, caracterizam-se essas manifestações patológicas como não sendo causadas pelo recalque diferencial.

Um tipo de indício de fissuras devido ao recalque é quando há presença de esmagamentos localizados, dando aparência de escamas. A fachada sul apresentou, em sua alvenaria, em alguns pontos, aparência de escamas, onde poderiam ser classificadas como fissuras devido ao recalque. Porém, como já analisado previamente, essas fissuras são de espessura muito fina e já com aparência de existência anterior, descaracterizando, então como causadas pelo recalque. E, por sua vez, as caracterizando como fissuras devido à contínua presença de umidade.

As fissuras horizontais e sequenciais seguindo a parte superior e inferior das vigas, como apresentado no mapa de danos das fachadas anteriormente, caracterizam situações de tração e compressão do concreto.

Após a ocorrência do recalque, o piso entorno às bases dos pilares no pavimento térreo sofreu rachaduras devido à movimentação dos pilares, assim como um pilar do pavimento térreo apresentou uma abertura vertical de extensão que pode ser classificada, de acordo com Oliveira [13], como rachadura, ou seja, 3mm. O muro de divisa do edifício com o terreno baldio, na lateral leste do terreno, possui algumas 
BORTOLI, M.F.; HIRANO, E.L.; BRESSIANI, L.; SAVARIS, G.; BALESTRA, C. E. T. ANÁLISE DAS MANIFESTAÇÕES PATOLÓGICAS DE UM EDIFÍCIO QUE SOFREU RECALQUE DIFERENCIAL. $4^{\circ}$ Simpósio Paranaense de Patologia das Construções (40 SPPC), artigo 4SPPC115, pp. 124 - 135, 2019. DOI: 10.4322/2526-7248.035

rachaduras verticais, acompanhando as juntas de assentamento da alvenaria (Figura 6). O muro encontra-se na extremidade de maior recalque diferencial do terreno.
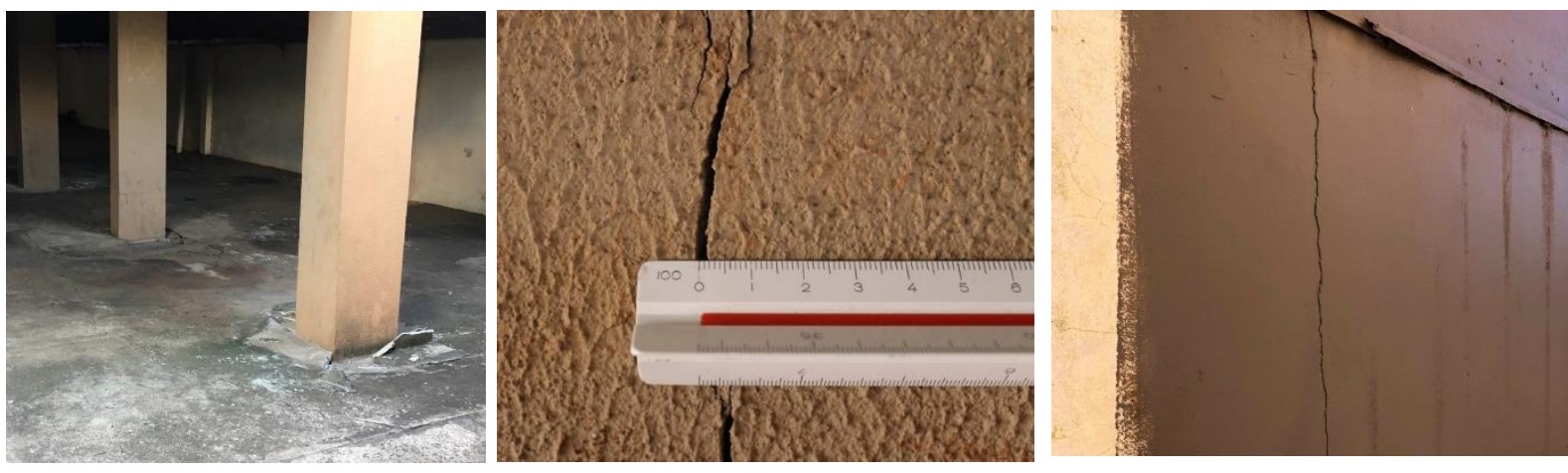

Figura 6: Análise da abertura do pilar no pavimento térreo

As anomalias originadas nas bases dos pilares se devem ao movimento negativo que a estrutura do edifício fez durante o recalque diferencial. Fato esse que acabou ocasionando as fissuras no pavimento térreo ao redor dos pilares.

No caso da rachadura do pilar, esta pode ter sido originada pelo recalque diferencial. O fato de apenas um pilar apresentar tal manifestação patológica pode ser explicado pelo pilar estar sobre um ponto crítico do recalque. Ou seja, na situação do recalque, - local onde se encontrava esse pilar, pode ter vindo a ter uma movimentação negativa superior e mais brusca que as demais, que pode ter ocasionado uma solicitação de tensões maiores, vindo a causar tal anomalia. Além disso, o laudo pericial também apresenta tal manifestação patológica como sendo causada pelo recalque.

Quanto a rachadura do muro, esta pode ser configurada como devido ao recalque. De acordo com Thomaz [9], locais que sofrem recalque diferencial causam rachaduras, fendas ou brechas nos muros conforme apresentado no muro em questão. Onde a disposição desta é acompanhando a junção argamassada da alvenaria.

\subsection{Análise do reforço de fundação}

Ao acompanhar o processo de recuperação do edifício como um todo, verificou-se que a solução aplicada para o reforço de fundação do edifício foi o reforço com estacas mega. Este sistema é conhecido também como estacas de reação, onde são colocados cilindros de metal ou concreto ao lado da fundação já existente.

O método consiste em escavação com aberturas de pelo menos 1,00x1,50m e com profundidade ideal para o trabalho ser realizado. A partir desta cota se cravam estacas, com o diâmetro necessário, ao lado da fundação já existente com o auxílio de macaco hidráulico, de modo a se aumentar a resistência da fundação. A Figura 7 apresenta imagens da abertura realizada ao lado da fundação existente e as estacas de concreto utilizadas para o reforço. 

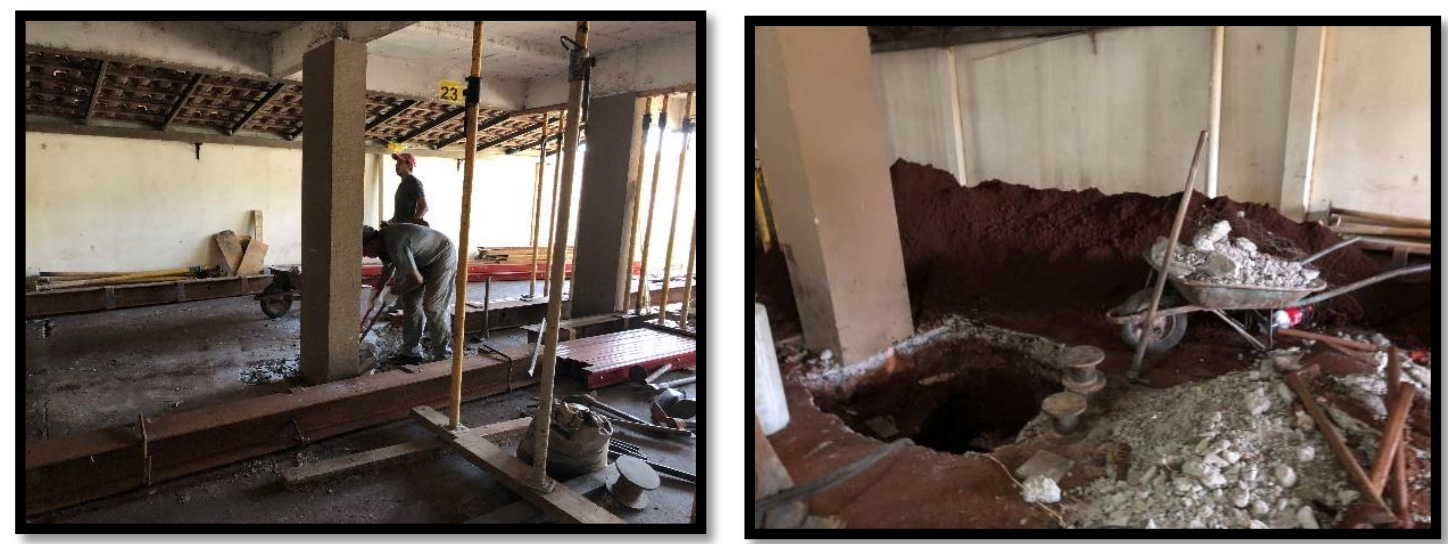

Figura 7: Reforço da fundação

Os principais materiais utilizados para o reforço de fundação são as estacas de concreto que são implantadas no solo como estruturas para complementação da fundação e os macacos hidráulicos (Figura 8).
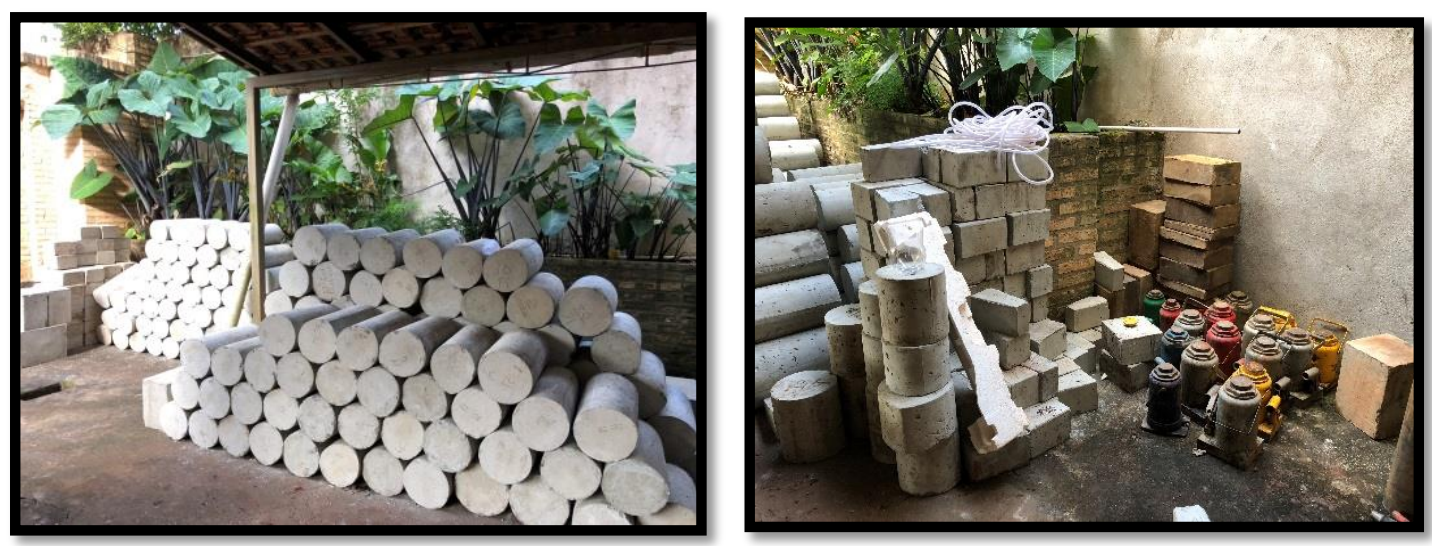

Figura 8: Peças de concreto para reforço

Para realização do reforço no edifício analisado, com a cravação das novas estacas, estas foram ligadas às já existentes por vigas, para que os esforços pudessem ser distribuídos entre todas as estacas. A Figura 9 demonstra momentos em que o reforço de fundação estava sendo realizado, conforme o método explicado anteriormente.
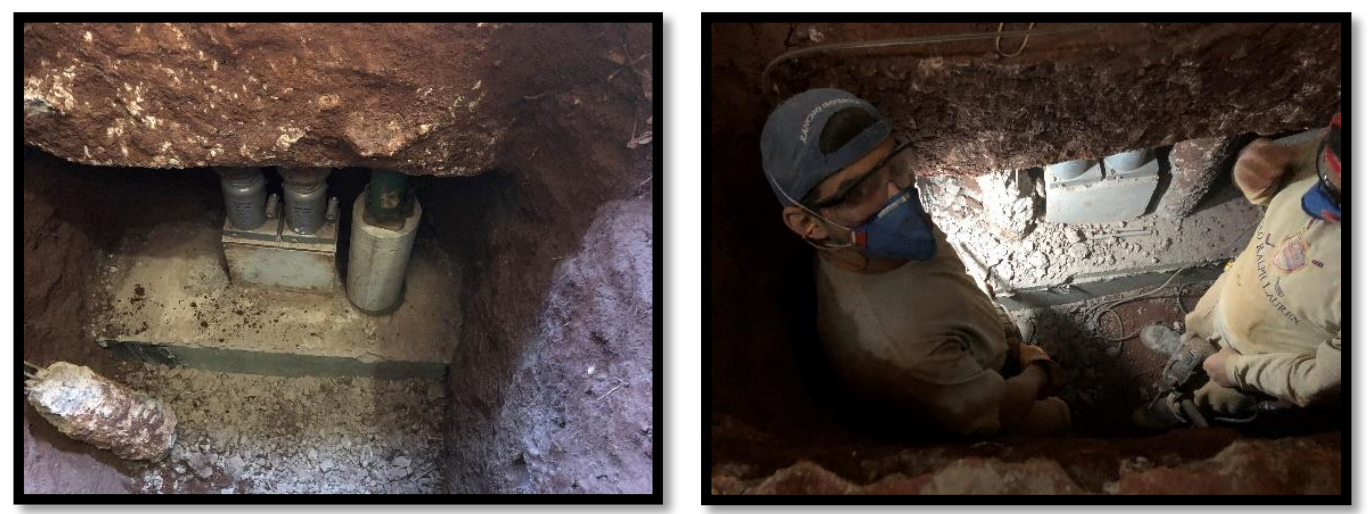

Figura 9: Realização do reforço 
BORTOLI, M.F.; HIRANO, E.L.; BRESSIANI, L.; SAVARIS, G.; BALESTRA, C. E. T. ANÁLISE DAS MANIFESTAÇÕES PATOLÓGICAS DE UM EDIFÍCIO QUE SOFREU RECALQUE DIFERENCIAL. $4^{\circ}$ Simpósio Paranaense de Patologia das Construções (40 SPPC), artigo 4SPPC115, pp. 124 - 135, 2019. DOI: 10.4322/2526-7248.035

A escolha do método de reforço deve levar em consideração vários detalhes, como as características do solo local, as características da estrutura em si, como também os requisitos e tipos de situações que cada tipo de método se enquadra. Neves [14] e Correia [15], dividem os tipos de reforços em reforços sem aprofundamento e com aprofundamento.

Como apresentado no laudo, o solo do local possui uma camada com presença de água, o que impossibilita que tipos de reforços sem aprofundamento sejam realizados, uma vez que estes não são executados em solos como encontrado no terreno. Com isso, tem-se a limitando para a situação, a soluções com a aplicação de reforço com aprofundamento.

Com a necessidade de se transferir as cargas para profundidades maiores, de acordo com Neves [14] e Correia [15], os tipos de reforços mais usuais tratam-se da execução de estacas metálicas, de madeira ou de concreto armado, que são cravadas no solo, ou no caso do concreto armado podem também ser moldadas no solo, além da possibilidade da utilização de microestacas como reforço.

A última solução (microestaca) se destaca das demais pela possibilidade de execução em espaços limitados e com reduzido diâmetro, o que a tornaria uma solução possível, visto que as demais necessitam de espaços maiores para a sua execução, devido aos tamanhos das estacas para reforços e equipamentos para cravação ou escavação. Porém, esta pode ser realizada de modo escavado ou cravado. No modo escavado, pela tipologia do solo, torna o método inviável, ao passo que a cravada gera muita vibração. De modo a tornar a solução inviável.

A inviabilidade de executar o reforço com os métodos apresentados confirma a escolha mais adequada da solução aplicada, onde se levou em consideração os pontos importantes do caso em questão. Foi adotado o sistema que não sofreu interferência pela presença de água numa camada de solo, atingindo a camada abaixo dessa, de maior resistência. Assim como não propagou vibrações de modo a interferir na estabilidade da estrutura e os equipamentos eram compatíveis com 0 local a ser executado o reparo.

\section{Considerações finais}

Após o levantamento das fissuras e com base na literatura, juntamente com o histórico do caso e a análise do laudo pericial, foi possível estudar cada tipo de fissura encontrada no edifício, buscando cada possível causa.

Em todos os apartamentos foram encontradas fissuras horizontais e em 45․ As fissuras horizontais foram causadas devido às diferentes movimentações térmicas dos elementos de concreto e alvenaria. Já às com configuração em 45ำ foram ocasionadas provavelmente pelo recalque diferencial, visto que suas características apontam para tal causa.

Da mesma forma, foram encontradas manifestações patológicas nas bases dos pilares no pavimento térreo, no muro de divisa sobre o local mais crítico de recalque, como também em um pilar do pavimento térreo. Essas foram classificadas como 
BORTOLI, M.F.; HIRANO, E.L.; BRESSIANI, L.; SAVARIS, G.; BALESTRA, C. E. T. ANÁLISE DAS MANIFESTAÇÕES PATOLÓGICAS DE UM EDIFÍCIO QUE SOFREU RECALQUE DIFERENCIAL. $4^{\circ}$ Simpósio Paranaense de Patologia das Construções (40 SPPC), artigo 4SPPC115, pp. 124 - 135, 2019. DOI: 10.4322/2526-7248.035

rachaduras e apresentaram características e particularidades que apontam 0 recalque diferencial como o causador das mesmas.

Alguns métodos foram levantados na literatura para reforço da fundação, como reforço com estacas metálicas, de madeira, de concreto armado e microestacas, que foram descartados, uma vez que seus métodos de execução, quando cravados geram muita vibração no solo, podendo causar perturbações na estrutura. Ao passo que quando executados de forma escavada, no caso do concreto armado, torna-se impossibilitado pela presença de água em camadas de solo.

Desta forma, o método de estacas mega implantado através de macacos hidráulicos, foi o mais propício e adequado para a situação, uma vez que este pode ser executado nas condições e particularidades encontradas no caso em estudo.

\section{Referências}

[1] VALENTE, A. P. V.; SILVA, A. P.; CALIXTO, J. M. F. (2009) Análise dos processos de recuperação de manifestações patológicas: trincas e impermeabilização. Construindo, Belo Horizonte, v.1, n.2, p.7-11, jul./dez.

[2] TUTIKIAN, B.; PACHECO, M. (2013) Inspeção, diagnóstico e prognóstico na construção civil. ALCONPAT Int. Boletín Técnico, Mérida, México, n. 1, p. 3-15, mar. 2013.

[3] MILITITSKY, J.; CONSOLI, N. C.; SCHNAID, F. (2015) Patologia das fundações. 2. ed. rev. ampl. São Paulo: Oficina de Textos.

[4] VERÇOZA, E. J. (1991). Patologia das edificações. 10. ed. Porto Alegre: Sagra.

[5] TINOCO, J. E. L. (2009) Mapa de danos: recomendações básicas. Textos para Discussão, v. 43, Olinda, (Série 2: Gestão de Restauro).

[6] BUILDING RESEARCH ESTABLISHMENT. Housing defects reference manual. Londres, E. \& F. N. Spon, 1994.

[7] COLARES G.M. (2006) Programa para análise da interação solo - estrutura no projeto de edifícios. Dissertação (Mestrado) - Universidade de São Paulo.

[8] JUNIOR, O.G.H. (2002) Influência de recalques em edifícios de alvenaria estrutural. Dissertação (Doutorado) - Escola de Engenharia de São Carlos, Universidade de São Paulo.

[9] THOMAZ, E. (1998) Trincas em edifícios: causas, prevenção e recuperação. São Paulo: Pini.

[10] THOMAZ, E.C. S. (2003). Fissuração: 168 Casos Reais. Rio de Janeiro: Instituto Militar de Engenharia, 2003. p. 286.

[11] SAMPAIO, M.B. (2001) Fissuras em edifícios residências em alvenaria estrutural. Dissertação (Mestrado) - Escola Politécnica, Universidade de São Paulo. 
BORTOLI, M.F.; HIRANO, E.L.; BRESSIANI, L.; SAVARIS, G.; BALESTRA, C. E. T. ANÁLISE DAS MANIFESTAÇÕES PATOLÓGICAS DE UM EDIFÍCIO QUE SOFREU RECALQUE DIFERENCIAL. $4^{\circ}$ Simpósio Paranaense de Patologia das Construções (40 SPPC), artigo 4SPPC115, pp. 124 - 135, 2019. DOI: 10.4322/2526-7248.035

[12] ALEXANDRE, I.F. (2008) Manifestações patológicas em empreendimentos habitacionais de baixa renda executados em alvenaria estrutural: uma análise da relação de causa e efeito. Dissertação (Mestrado) - Universidade Federal do Rio Grande do Sul.

[13] OLIVEIRA, A. M. (2012) Fissuras, trincas e rachaduras causadas por recalque diferencial de fundações. 96 f. Monografia (Especialização) - Universidade Federal de Minas Gerais, Belo Horizonte.

[14] NEVES, M. J. N. (2012) Técnicas de recalçamento e reforço de fundações: metodologias, dimensionamento e verificações de segurança. 165f. Dissertação (Mestrado em Engenharia Civil) - Universidade Técnica de Lisboa, Lisboa.

[15] CORREIA, J. N. D. (2014) Reforço de fundações de edifícios. 104f. Dissertação (Mestrado em Engenharia Civil) - Universidade Técnica de Lisboa, Lisboa. 